\title{
Compaction analysis and optimisation of convex-faced pharmaceutical tablets using numerical techniques
}

\author{
Ahmad Baroutaji ${ }^{1}$, Sandra Lenihan ${ }^{2,}$ Keith Bryan ${ }^{2}$ \\ (1) School of Engineering, Faculty of Science and Engineering, University of Wolverhampton, Telford, UK \\ (2) School of Mechanical, Electrical and Process Engineering, Cork Institute of Technology, Cork, Ireland
}

\begin{abstract}
Capping failure, edge chipping, and non-uniform mechanical properties of convexfaced pharmaceutical tablets are common problems in pharma industry. In this paper, Finite Element Modelling (FEM) and Design of Experiment (DoE) techniques are adopted to find the optimal shape of convex-faced $(\mathrm{CF})$ pharmaceutical tablet which has more uniform mechanical properties and less capping and chipping tendency. The effects of the geometrical parameters and friction on the compaction responses of convex-faced pharmaceutical tablets were first identified and analysed. The finite element model of the tabletting process was generated using the implicit code (ABAQUS) and validated against experimental measurements. Response Surface Methodology (RSM) was employed to establish the relationship between the design variables, represented by the geometrical parameters and the friction coefficient, and compaction responses of interest including residual die pressure, the variation of relative density within the tablet, and the relative shear stress of the edge of the tablet. A statistical-based optimisation approach is then employed to undertake shape optimisation of CF tablets. The obtained results demonstrated how the geometrical parameters of $\mathrm{CF}$ tablet and the friction coefficient have significant effects on the compaction behaviour and quality of the pharmaceutical tablet.

Keywords: Capping failure, edge chipping, tabletting, convex-faced, DoE, FEM, RSM, optimisation, residual radial pressure.
\end{abstract}




\section{Introduction}

Tabletting is the process during which pharmaceutical powders are compacted in a die to produce a pharmaceutical tablet as a solid dosage of medication [1]. The powders used in tabletting are complex mixture of several ingredients including the active pharmaceutical ingredient (API), excipients, lubricants, binders, fillers and so on. Manufacturing a high quality tablet is a challenging task as many well-known defects may develop during the compaction of powders such as capping, lamination, chipping and binding [2]. Generally, the tabletting process is influenced by several factors including formulation properties, process parameters such as speed of compaction, geometrical factors including punch shape and tooling dimensions, lubrication, and ambient conditions such as temperature and relative humidity. Investigating the influence of such factors without a knowledge-based exclusion of the insignificant variables may dramatically increase the number of experiments that are required to attain the proper knowledge. Therefore, the Design of Experiment (DoE) approach has recently received increased adoption to attain a scientific understanding of the manufacturing process in pharmaceutical industry [3], [4]. The main advantage of DoE is that it allows for developing statistical-based models that explain the relationship between variables and the observed quality characteristics. Such models can further be used in optimization algorithm for determining the optimal combination of various factors and enable manufacturing of pharmaceutical tablets with the desired properties [5].

Issues in tabletting process can be investigated experimentally and numerically. Experimental techniques are expensive in nature requiring significant set-up with instrumentation and provide limited information pertaining to the process. However, numerical computational modelling tools, such as Finite Element Method (FEM), are 
very useful techniques providing access to unique results that cannot readily be attained from experimental tests. Recently, modelling techniques were successfully implemented to attain a better insight on the various aspects of the tabletting process such as tablet failure mechanism [6], [7], [8], [9], [10], temperature evolution during the process [8], [11], stress and density distributions within the tablet [12], effect of punch shape [6], [13], and effect of friction [14].

Pharmaceutical tablets are produced with various shapes. Traditionally, tablets were manufactured as cylindrical items with flat ends. More recently, tablets are no longer flat but possess more complexity in shape, such as convex-faced (CF) tablets, to enable better performance on post compaction processing such as film coating and product identification [15]. However, the convex-faced tablets demonstrate a greater tendency for capping than the flat-faced one [16]. Capping is the most common tablet's defect in which a tablet is separated into two parts: cap and body. Evaluation of capping tendency and predicting its occurrence during tabletting is of great importance because capping heavily influences the quality of the tablets during the post-compaction processes such as coating, handling, packaging and transport. Therefore, researchers and scientists have developed several experimental and numerical methods for predicting capping tendency. Nakamura et al [17] developed an evaluation method of capping tendency using recovery energy during the relaxation phase and the plastic deformation energy during compression phase. Kuppuswamy et al [18] evaluated capping tendency using indentation fracture test. Furukawa et al [10] estimated capping tendency in single-radius and double-radius tablets using a simple method that is based on the variation in plastic strain during a diametrical compression test. Authors used numerical simulations to calculate plastic strains. The main causes of capping are not clear but most studies have postulated 
that it may be related to the local stress concentration due to elastic recovery [12], [19], higher residual die pressure at the end of relaxation phase [16], [20] and poor strength due to weak binding between particles [21].

Successful compaction of high quality CF tablets, which contain uniform mechanical properties and low capping tendency, continues to remain a significant challenge. It requires a sound understanding of the impact of various process parameters on the product's attributes and also finding the optimal settings of these factors that yield pharmaceutical tablets with the desired properties.

Despite the abundance of research on the compaction of convex-faced tablets, the effect of the geometrical parameters of the tablet on the compaction process has received limited attention. Most previous studies [7], [22] focused on the effect of curvature and thickness whereas the effect of tablet's diameter was ignored. Also, to the best of authors' knowledge, shape optimisation of convex-faced tablets is not yet presented in public domain. Thus, in the present study, FEM and DoE tools were combined to study the effects of the geometrical parameters on the compaction of the convex-faced tablets. The DoE techniques were applied on the compaction responses calculated from the finite element modelling to systemically analyse and optimise the tabletting process in a quick and cost-effective fashion. Variation in relative density, residual die pressure, and relative shear stress of edge region were selected as compaction responses whereas the diameter, radius of curvature, and friction coefficient were set as design variables. The relationship between the compaction responses and geometrical parameters were described mathematically using RSM. The optimal geometrical factors that yield a high quality CF tablet were determined using desirability optimisation approach. 


\section{Materials and methods}

\subsection{Powder}

Microcrystalline Cellulose (MCC) Avicel PH 102 pharmaceutical excipient (manufactured by FMC BioPolymer, Cork, Ireland) was used in this study. This excipient is widely used in pharmaceutical tablet formulations. The shape of MCC particles are irregular, with an average particle size of $100 \mu \mathrm{m}$ and size distribution between 20 and $200 \mu \mathrm{m}$ according to the manufacturer's specifications. The bulk and true densities of MCC powder, according to the manufacturer's specifications, are $300 \mathrm{~kg} \cdot \mathrm{m}^{-3}$ and $1590 \mathrm{~kg} \cdot \mathrm{m}^{-3}$, respectively.

\subsection{Multi-objective optimisation}

\subsubsection{Formulation of optimisation problem}

The general mathematical formulation of a multi-objective optimisation problem is presented in equation 1

$$
\left\{\begin{array}{cc}
\text { Minimise } & f(x)=\left[f_{1}(x), f_{2}(x), \ldots, f_{i}(x)\right] \\
\text { s.t } & x^{l} \leq x \leq x^{u}
\end{array}\right.
$$

Where $x=\left(x_{1}, x_{2}, \ldots, x_{k}\right)$ is the vector of $\mathrm{k}$ design variables, $x^{l}$ and $x^{u}$ are respectively the lower and upper limits of the design variables, $f(x)$ is the objective function.

The tabletting process can be optimised in different ways depending on various criteria, such as precise shape, friction coefficient, punch forces, die pressure or uniform distribution of mechanical properties. The design variables can be selected to represents the process parameters, such as compaction velocity, punch forces and dwell time, or the geometrical parameters such as die diameter and punch curvature. The optimal design criterion of this study is focused on the shape optimisation to 
achieve a high quality compact. Defining the relationships between key compaction attributes and the geometrical parameters will lead to a better tabletting process. Thus, the geometrical parameters of the convex-faced tablets including the diameter (D) and radius of curvature (R) are considered as unknown design variables. Also, it is well reported in the literature, [14], [23], that the friction between the compaction tools and the powder have a dramatic influence on the performance of the final tablet and for this the friction coefficient $(\mu)$ was taken as a design variable in this study to investigate the role of frictions on the compaction responses. Among the various compaction responses, the maximum variation of relative density, residual die pressure, and the relative shear stress affecting the edge of the tablet were selected as the responses of interest in this study. These responses have a great influence on the quality and success of the tabletting process. The relative density variation is the difference between the maximum and minimum values of relative density in the final CF tablet as shown in equation 2

$$
R D V=\left|R D_{\max }-R D_{\min }\right|
$$

Where RDV is the relative density variation, $R D_{\max }$ and $R D_{\min }$ are the maximum and minimum relative densities observed within the CF tablet.

It is well established that a pharmaceutical tablet contains a non-uniform density distribution due to inherent frictional effect between the powder and compaction tooling. Regions of lower density have lower mechanical strength thus prone to defect occurrences such as capping. Additionally, the density variation leads to different properties in different regions inside the tablet and this affects the mechanical responses of the tablet during post-compaction processes, such as coating, transportation, packing, as well as dissolution behaviour. Thus, minimising 
the relative density variation is vital for attaining a tablet with uniform mechanical properties and improving tablet quality.

Residual die pressure was selected as the second optimisation objective in this study due to its role in capping of CF tablets. Many studies have reported that tablets with greater residual die pressure (RDP) at the end of unloading stage have higher capping tendency [16], [20]. High RDP at the end of unloading promotes larger shear stresses inside the compact which could exceed tablet strength causing capping. On the removal of the upper punch on completion of compaction and while the tablet is still inside the die, the tablet is compressed radially by the residual die pressure (RDP). Figure 1 shows the stress state of a tablet at the end of decompression stage and represented by Mohr circle. It is evident from this figure that the higher RDP produce higher shear stress which may lead to cracks inside the tablets. Additionally, the RDP dominates the stresses generated during the ejection phase. The higher RDP infers greater contact between the powder and the die wall and this gives rise to a greater ejection force which induces greater stresses during the ejection phase and this may lead to various defects. Thus, minimising the RDP leads to less capping tendency of the produced tablets.

Typically, chipping failure of a pharmaceutical tablet occurs at its edge which is due to the high stress concentration caused by the radial elastic recovery of the tablet as it emerges from the die during the ejection phase [6]. If the stress generated during the ejection phase is greater than the strength of tablet, edge chipping failure occurs. The strength of a region inside a compact can be linked to its Relative Density (RD) as higher RD deduces more material is placed in the region and thus higher strength. In order to estimate the edge chipping failure tendency of a tablet in this study, a new measure called as Relative Shear Stress (RSS) which represents the ratio between the 
shear stress generated at the edge region during the ejection and relative density of that region is used, as illustrated in Equation 3.

$$
R S S=\frac{\tau_{E}}{R D_{E}}
$$

Where $\tau_{E}$ and $R D_{E}$ are the shear stress and the relative density of the edge region calculated at the instant the tablet emerges from the die. RSS measures the relative effect of the shear stress generated during the ejection to the strength of that region. The higher magnitude of RSS infers higher tendency of edge chipping and viceversa. Thus, the RSS was selected as the third design response as an estimation of the chipping occurrence during the ejection.

\subsubsection{Surrogate modelling}

In order to generate a solution for the optimisation formula as denoted in equation 1, the compaction responses of interest, in this study RDV, RDP, and RSS should first be described mathematically. However, the powder compaction process is a highly nonlinear mechanics problem therefore it is challenging to establish a suitable analytical solution for it. Thus as an alternative to analytical models, Response Surface Methodology (RSM) was used to construct models which relate the compaction responses to different design variables. The advantage of employing RSM is that the compaction behaviour of powders in a particular design space can be identified through performing a reduced number of experiments at sampling design points. The sampling design points can be generated using different methods offered by Design of Experiment (DoE) such as factorial, Box-Behnken design (BBD), central-composite design (CCD), D-optimal. The adequacy of the developed Response Surface (RS) models is verified via the analysis of variance (ANOVA) to 
confirm their capability in predicting the compaction responses. Different statistical measures were used to inspect the statistical significance of the RS models such as R-square parameter, Adjusted R-square, and Adeq Precision. Once the RS models have been developed and tested for adequacy, they can be used in the multi-objective optimisation formula.

\subsubsection{Optimisation algorithm}

Typically, the solutions of the multiobjective optimisation problem, as shown in equation 1, can be obtained by two methods. The first method aims to investigate each of the objective functions independently and yield multiple optimum candidates that are known as the 'Pareto optimal' solutions. The 'Pareto optimal' solutions can be found using several optimisation algorithms such as Genetic Algorithm (GA) [24]-[26], Swarm Optimisation (MOPSO) algorithm and so on. Alternatively, the second solution method combines all multiple responses into a single non-dimension cost objective function, called an overall desirability function or cost objective function, in terms of a relative performance measure and generates one solution for the optimisation problem. This solution method can be applied by using weighted average method or the desirability approach. In fact, the desirability approach converts the multi-objective optimisation problem into a single objective problem by formulating the overall desirability function. This desirability function takes a value between 0 and 1 and the optimal solution is the one with the greatest desirability, i.e. the value of the desirability function is closer to 1 [27].

In the current study, the multi-objective optimisation formula is solved using the desirability approach [27]-[30]. This technique has received considerable attention for solving the multi-objective optimisation problems due to its simplicity, relatively 
low computational cost and rapid convergence. The main steps for generating the optimal solutions of the multi-objective problem using the desirability approach is shown in Figure 2.

\subsection{Simulations}

The experimental measurements of tablet local density and residual die pressure require non-standard instrumented compaction equipment which involves, to some extent, significant set-up and cost. However, such information can be readily attained by developing computational model of the compaction process such as FEM. The Finite Element Method (FEM) is widely used in lieu of experimental work for fast and time-effective engineering design. It has been proven, in many previous studies, that FEM is a very effective analysis and optimisation tool for various powder compaction applications including the tabletting process.

\subsubsection{FE model}

A commercial finite element package, ABAQUS (Dassault Systèmes, VélizyVillacoublay, France), was employed for creating the FE models of the die compaction for pharmaceutical powders. The finite element model consists of the upper and bottom punches, die walls, and the powder bed. The upper punch was modelled as a rigid body and constrained to move vertically along the y-axis. The bottom punch and die walls were also modelled as rigid entities with all rotations and translations being fixed. The powders were modelled as continuum media by using a 2D-axisymmetric stress element (CAX4R) that has four nodes. Elasticplastic material model based on Drucker-Prager Cap (DPC) model was employed to represent the behaviour of the powder during the compaction. The DPC model [31] 
is used significantly for modelling pharmaceutical tablet [12], [8], [22] and [16] due to its capability of representing the various phenomena associated with compaction such as shear flow, densification and hardening. A hardening mechanism was used to include the hardening behaviour of the powder during the process. The DPC model parameters of MCC and the calibration procedure were reported by same authors previously [32]. The user subroutine "USDFLD" was developed to update the material properties in relation to relative density changes. A surface to surface contact type with finite sliding formulation was employed to define the contact between the powders and compaction tools. All models were subjected to axisymmetric boundary conditions in order to reduce simulation solving times. Large strain deformation was incorporated to the finite element model as powders experience significantly high compaction displacement. The loads were defined by applying the predefined displacement on the pilot node, which was also used to gather the reaction force from each node. Figure 3 illustrates the axisymmetric finite element model of the MCC powder.

\subsubsection{Experimental set-up for validation of FE model}

In order to check the predictive capabilities of the constructed Finite Element (FE) model, the predictions of FE model were compared against experimental measurements attained from a hydraulic compactor (INSTRON Model \#8872). A 12 $\mathrm{mm}$ cylindrical die and convex-faced punches with a radius of curvature equal to 24 $\mathrm{mm}$ were used to compact MCC powder. A specific quantity of MCC was compressed by the upper punch to different levels of compaction pressure ranging from 20 to $50 \mathrm{MPa}$. The compression (loading) and decompression (unloading) speed was set to $3 \mathrm{~mm} \mathrm{~s}^{-1}$. The load transducer was accurately calibrated to ensure 
the reliability of the measurements. The parameters of the upper punch displacement and force were measured every $0.1 \mathrm{~ms}$. In order to minimise the influence of the friction between the compaction tooling and the powders, a small quantity of magnesium-stearate was used to lubricate the die wall and punches. On completion of compaction, the tablet was ejected from the die where its dimensions and weight were recorded to determine its corresponding density.

\section{Results and discussion}

\subsection{Validation of FE model}

To validate the FE model in this study, axial pressure as a function of axial displacement; and thickness of tablet as a function of compaction pressure were considered. These parameters were used for validating the FE model of a tableting process in previous studies [10], [12], [13], [19]. The accurate prediction of the tablet thickness not only ensures that the simulated tablet has an identical shape to the actual tablet one but also indicates that both tablets have the same average density and thus have comparable density variation within the tablet. Since RDP was taken as a response in this study, the axial pressure is another important parameter to be considered for $\mathrm{FE}$ model validation. It is known that the axial to radial stress transmission during the decompression stage is a function of the Poisson's ratio of the powder [12]. Thus, the accurate numerical prediction of the maximum axial pressure applied to the powders at the end of the compaction stage indicates that the FE model can provide accurate prediction of the residual die pressure at the end of decompression stage.

A FE element model was constructed where the initial height of the powder model was set to $9.5 \mathrm{~mm}$ corresponding to approximately $0.465 \mathrm{~g}$ of MCC used in the 
experiments. A friction coefficient value of 0.1 was employed for all contact pairs. This value of friction coefficient was also used by other researchers, [33] and [13], for similar investigation. Figure 4 presents a comparison between experimental measurements and predicted FE results. It can be seen from Figure 4 (a) that the numerical model slightly overestimates the axial pressure during the early and middle stages of the loading phase and then it starts providing very good predictions towards the end of this phase. For the unloading phase, the numerical model shows less elastic recovery than the experiments and this could be attributed to non-linear elastic behaviour of the powder which is not well captured by the DPC model [16], [33]. Overall, the simulation results provide good agreement with experimental results and this indicates that the developed FE model is sufficiently accurate and can subsequently be used as a robust tool to predict the responses of the tabletting process.

\subsection{Development and accuracy of the RS models}

Central-composite design (CCD) was selected to construct the sampling design points. CCD is a highly efficient method that reduces the number of required runs for constructing high quality RS models. The geometrical parameters of the convex tablet, including radius of curvature (R) and die diameter (D), and friction coefficient $(\mu)$ were selected as design variables. In order to ensure that the aforementioned parameters are the only variables within this study, the same quantity of MCC powder and same compaction pressure were used for all design points. This means that, among all design points, initial heights of powder beds, the total travel distances of the top punch, the thicknesses of the tablets were all different. The upper and lower limits of the geometrical parameters with all sampling points are illustrated in 
Table 1. The limits of the geometrical parameters, as shown in Table 1, yields diameter to curvature $(\mathrm{D} / \mathrm{R})$ ratios which are within the standard used by the manufacturers for micro and shallow convex-faced tablets [34]. FE models were created for the tabletting process representing the sampling design points and the responses of interest (RDV, RDP, RSS) were determined as shown in Table 2. The RS models of the RDV, RDP, and RSS compaction responses in terms of the geometrical factors are outlined in equations 4,5 , and 6 respectively

$$
(R D V)^{0.32}=0.193+0.036 \times D-4.09 \times 10^{-3} \times R+0.201 \times \mu
$$

$$
\begin{aligned}
(R D P)^{-3}= & 4.99 \times 10^{-3}-3.97 \times 10^{-4} \times D+4.75 \times 10^{-5} \times R-7.85 \\
& \times 10^{-4} \times \mu
\end{aligned}
$$

$$
\begin{aligned}
(R S S)^{-2.16}= & -2.035+0.1568 \times D+0.108 \times R+0.560 \times \mu+5.52 \\
& \times 10^{-3} \times D \times R-0.116 \times D \times \mu-0.036 \times R \times \mu \\
& -0.0127 \times D^{2}-3.264 \times 10^{-3} \times R^{2}+3.212 \times \mu^{2}
\end{aligned}
$$

Analysis of variance (ANOVA) was performed to verify the adequacy of the generated RS models. Table 3 summarises the statistical measurements for the aforementioned RS models for RDV, RDP and RSS. It can be seen that all models show high F-value and very low p-value which confirm that these models are significant. Additionally; the adequate precision ratios of all models are higher than 4 which illustrates that the models yield minimal noise. Furthermore, the models exhibit high R-squared (coefficient of determination) values and they also demonstrate an excellent agreement between the predicted R-squared and adjusted 
R-squared. The relationship between the numerical results, obtained from FE simulations, and those predicted by the RS models at the design points are shown in Figure 5. It is clear that all RDV, RDP, and RSS values lie on the best-fit line (diagonal line) and this means that the RS models have excellent predictive capabilities. To further confirm the accuracy of the RS models, four simulations at independent confirmation points, within the design space, were performed. The compaction responses, obtained from FE modelling of the confirmation points, were compared with those predicted by the RS models and excellent agreement was obtained, as shown in Table 4. All of the aforementioned measurements prove that the developed RS models are accurate and valid and thus they can be used to navigate the whole design space and in the further optimisation design.

\subsection{Parametric analysis}

The RS models developed in the previous section are used to perform a parametric analysis of the tabletting process

\subsubsection{Effect of design variables on RDV}

It is important to consider how the relative density (RD) changes in $\mathrm{CF}$ tablets prior to investigating the effects of geometrical parameters on relative density. Figure 6 presents the final relative density distribution for convex-faced tablets with different geometrical dimensions at the end of decompression stage. It can be seen that all CF tablets show similar pattern of RD distribution in which high density region develops at the top corner of the moving upper punch while the low density region forms at the centreline of the tablet. The non-uniform distribution of density in CF tablets is caused by the frictional effects and the geometrical shape of the punch. Concaveshaped punches do not generate uniform pressure along the tablet's diameter. At the 
beginning of the tabletting process, the concave-shaped punch comes first in contact with the regions at the top corner of the powder bed inducing a local densification in these locations which tends to propagate vertically and radially. With the frictional effect between the powder and compaction tools, the radial and vertical motions are limited and thus the densification is restricted at the top circumference of the powder. As the compaction process progress, the upper punch continues to move downward and starts interfacing with the central region of the powder bed and only then the powder in this region starts to densify leading to a formation of less compressed region around the top central of the tablet.

Figure 7 illustrates the variation of the RDV with diameter and radius of curvature for two different friction coefficients. It is seen that the RDV increases as D increases, $\mathrm{R}$ decreases, and $\mu$ increases. To understand this trend, a schematic diagram of a concave punch face with different sizes is presented in Figure 8. It can be seen that by increasing $\mathrm{D}$ or decreasing $\mathrm{R}$, the punch depth at the central axis increases and this delay the compression of the central region comparing to the top circumferential region leading to a greater variation in the density between the two regions. Also, increasing the friction coefficient creates more resistance towards powder motion in the axial and radial directions restricting the densification more at the top corner and resulting a higher RDV. It is apparent that a CF tablet with D of $12 \mathrm{~mm}, \mathrm{R}$ of $22 \mathrm{~mm}$, and $\mu$ of 0.3 demonstrates the greatest changes in local relative density. It yields approximately $122 \%$ higher RDV than a tablet with a diameter of $10 \mathrm{~mm}$, radius of curvature of $26 \mathrm{~mm}$ and friction coefficient of 0.1 . 


\subsubsection{Effect of design variables on RDP}

The radial pressure in this study was calculated, from the numerical models, by dividing the normal contact force between the powder and the die-wall by the area of the total contact surface.

Figure 9 demonstrates two 3D surface plots of RDP with $\mathrm{D}$ and $\mathrm{R}$ for friction coefficients of 0.1 and 0.3 , respectively. It is evident from this plot that RDP increases when the diameter increases, radius of curvature decreases, and friction increases. For example, when $\mathrm{R}$ equals to $22 \mathrm{~mm}$ and $\mu$ equals to 0.1 , increasing the die diameter from $10 \mathrm{~mm}$ to $12 \mathrm{~mm}$ increases the magnitude of RDP from $7.9 \mathrm{MPa}$ to $9.4 \mathrm{MPa}$; which account for a $20 \%$ increase in RDP. Similarly, for R equals to 22 $\mathrm{mm}$ and $\mathrm{D}$ equals to $10 \mathrm{~mm}$, increasing the friction coefficient from 0.1 to 0.3 lead to an increase of approximately 35\% in the RDP. Obviously, the CF tablet with D of 12 $\mathrm{mm}, \mathrm{R}$ of $22 \mathrm{~mm}$, and $\mu$ of 0.3 has the highest RDP. In order to understand how the geometrical parameters affect the RDP, a closer look at the decompression stage is required. Mazel et al [16] analysed the unloading stage of the biconvex tablet where they observed that the contact between the upper punch and tablet was lost gradually causing some radial elastic recovery of the convex part of CF tablet which in turn gave rise to an increase of the residual die pressure. With increasing $\mathrm{D}$ and/or decreasing R, the size of the convex part, as it can be estimated from Figure 8, becomes bigger which in turn may induce greater radial relaxation of the top central curved region upon the removal of the top punch leading to greater RDP.

In order to explain the relationship between the RDP and the stresses generated inside the tablet, Figure 10 was generated. This figure shows axial stress distribution at the end of decompression of CF tablets with different dimensions. It is evident that 
CF tablets contain regions under the effects of tensile stresses. These regions are risks areas which promote crack formation leading to capping and/or lamination failures of the tablets [35]. It is obvious that with increasing D and/or decreasing R, greater magnitudes of tensile stresses are produced at the risk regions and this could be directly linked to the higher values of RDP.

\subsubsection{Effect of design variables on RSS}

As previously explained in section 2.2.1, during the ejection phase as the tablet is emerging from the die, a radial relaxation occurs causing a very high stresses concentration in the corner region, as shown in Figure 11. These stresses may create cracks in that region leading to a failure mode known as edge chipping. However, if the edge region is compressed well and has sufficient strength, it can sustain the high stress and thus the edge chipping is less likely to occur. In order to attain a better estimation of the chipping occurrence, the Relative Shear Stress is introduced in this study which combines the stress generated during the ejection with the relative density of that region as an indication of its strength. The variation of RSS with the design variables is shown in Figure 12. It is clear that the RSS increases as diameter increases, radius of curvature decreases, and friction coefficient increases. The smallest value of RSS, which corresponds to design variables of $D=10 \mathrm{~mm}, \mathrm{R}=26$ and $\mu=0.1$, is approximately $20 \%$ less that the largest value observed at design variables of $\mathrm{D}=12 \mathrm{~mm}, \mathrm{R}=22$, and $\mu=0.3$. Punches with smaller $\mathrm{R}$ generate tablets with higher relative density at the edge region, as it can be shown in Figure 6, which is good for resisting edge chipping. However, it seems that tablets with smaller $\mathrm{R}$ store more elastic energies in the corner region after the unloading phase which 
induces higher shear stress during the ejection leading to higher tendency of edge chipping.

\subsection{Optimisation results}

The multi-objective optimisation formula in terms of RDV, RDP, and RSS as design responses, and $\mathrm{D}, \mathrm{R}$, and $\mu$ as design variables can be expressed as in equation 7

$$
\left\{\begin{array}{cc}
\text { Minmise } & R D V=f_{1}(D, R, \mu) \\
\text { Minmise } & R D P=f_{2}(D, R, \mu) \\
\text { Minmise } & R S S=f_{3}(D, R, \mu) \\
\text { s.t } & 10 \leq D \leq 12 \\
\text { s.t } & 22 \leq R \leq 26 \\
\text { s.t } & 0.1 \leq \mu \leq 0.3
\end{array}\right.
$$

The above equation was solved using desirability approach. Figure 13 shows a contour plot of the desirability objective as a function of geometrical parameters; i.e. $\mathrm{D}$ and $\mathrm{R}$, at the upper and lower conditions of friction. It is apparent that higher desirability can be achieved by reducing the diameter $\mathrm{D}$ and increasing the radius of curvature $\mathrm{R}$. The greatest desirability can be attained in the tablet with greater $\mathrm{R}$, smaller D and smaller $\mu$. Thus, the one can conclude that the optimal shape of the convex-faced tablets can be obtained by reducing the diameter, and increasing the radius of curvature, and decreasing the friction coefficient. Practically, increasing the radius of curvature of the punch indicates that a better design can be attained when using a Flat-Faced (FF) punch as the flat surface can be considered as a convex surface with an infinite R. To further investigate this, a finite element model of the flat-faced tablet, with the same quantity of powder and die diameter as in the optimal CF tablet, was created and the compaction responses were compared with optimal shape of CF tablet. Figure 14 compares the compaction responses in the optimal CF 
and FF tablets. The calculated RDV in FF tablet is 0.046 while it is equal to 0.091 in CF tablet which infers that FF tablet contains less RDV than the CF tablet. Furthermore, the RSS of a FF tablet is $1.138 \mathrm{MPa}$ and it is $47 \%$ smaller than that obtained during the producing of the optimal CF. Additionally, from Figure 14 (c), which shows the evolution of the die-wall pressure as a function of the radial pressure for FF and $\mathrm{CF}$ tablets, it is evident that a greater magnitude of RDP is evolved during the production of FF tablets. Similar observations were also reported in another study [16]. Therefore, from the above findings, it can be concluded that FF tablets are preferable over the CF tablets as they provide more desirable compaction responses in terms of RDV, RPD, and RSS. It should be noted that if no capping or chipping occurred during the compaction process, the CF tablet perform better than the FF configuration during the post-compaction processes such as coating, packaging, or handling.

\section{Conclusion}

Multi-objective optimisation study was performed on convex-faced pharmaceutical tablets based on numerical simulations and desirability approach. The goal was to study the effects of geometrical parameters and friction on the compaction responses and also to determine the optimal combination of these parameters for producing high quality CF tablets. RSM was used to develop models for the compaction responses as functions of geometrical parameters. The residual die pressure (RDP), after the decompression phase, and the variation of relative density within the tablet (RDV), and the Relative Shear Stress (RSS) were selected as the compaction responses of interest. These responses were observed to increase when increasing the diameter and friction coefficient, and decreasing the radius of curvature of $\mathrm{CF}$ 
tablets. Furthermore, the RS models were implemented in an optimisation algorithm to determine the geometrical parameters that satisfy best the three design requirements of tabletting including minimising the RDV, RDP, and RSS. The optimisation results indicated that the optimum configuration of CF tablets is the one that has a smaller diameter and greater radius of curvature. Therefore, it can be stated that in order to mitigate the failure risks during the compaction of $\mathrm{CF}$ tablets, it is preferable to produce tablets with smaller R/D ratio. Finally, the optimal configuration of $\mathrm{CF}$ tablet was compared against the FF tablet exhibiting that the latter have more favourable RDV, RDP, and RSS compaction responses.

In summary, the results obtained from this study shows that the quality of the CF tablet can be controlled by the proper selection of its dimensions including both the curvature and the diameter. Thus, the approach adopted in this paper could be of importance for engineers in the field of improving the quality of pharmaceutical products by design.

\section{Acknowledgements}

This work is funded by Pharmaceutical Manufacturing Technology Centre (PMTC) in Ireland under grant number TC-2013-0015.

\section{References}

[1] A. A. Rose and W. Kaialy, "Improved tableting behavior of paracetamol in the presence of polyvinylpyrrolidone additive: Effect of mixing conditions," Particuology, Jun. 2018.

[2] A. Baroutaji, K. Bryan, M. Sajjia, and S. Lenihan, "Mechanics and Computational Modeling of Pharmaceutical Tabletting Process," in Reference Module in Materials Science and Materials Engineering, 2017.

[3] M. Sajjia, A. B. Albadarin, and G. Walker, "Statistical analysis of industrial- 
scale roller compactor 'Freund TF-MINI model,'” Int. J. Pharm., vol. 513, no. 1-2, pp. 453-463, 2016.

[4] M. Sajjia, S. Shirazian, D. Egan, J. Iqbal, A. B. Albadarin, M. Southern, and G. Walker, "Mechanistic modelling of industrial-scale roller compactor 'Freund TF-MINI model,"' Comput. Chem. Eng., vol. 104, pp. 141-150, 2017.

[5] J. Rantanen and J. Khinast, "The Future of Pharmaceutical Manufacturing Sciences," J. Pharm. Sci., vol. 104, no. 11, pp. 3612-3638, 2015.

[6] M. S. Kadiri and A. Michrafy, "The effect of punch's shape on die compaction of pharmaceutical powders," Powder Technol., vol. 239, pp. 467477, 2013.

[7] C. Y. Wu, B. C. Hancock, A. Mills, a. C. Bentham, S. M. Best, and J. a. Elliott, "Numerical and experimental investigation of capping mechanisms during pharmaceutical tablet compaction," Powder Technol., vol. 181, no. 2, pp. 121-129, 2008.

[8] G. R. Klinzing, A. Zavaliangos, J. Cunningham, T. Mascaro, and D. Winstead, "Temperature and density evolution during compaction of a capsule shaped tablet," Comput. Chem. Eng., vol. 34, no. 7, pp. 1082-1091, 2010.

[9] S. Garner, E. Ruiz, J. Strong, and A. Zavaliangos, "Mechanisms of crack formation in die compacted powders during unloading and ejection: An experimental and modeling comparison between standard straight and tapered dies," Powder Technol., vol. 264, pp. 114-127, 2014.

[10] R. Furukawa, Y. Chen, A. Horiguchi, K. Takagaki, J. Nishi, A. Konishi, Y. Shirakawa, M. Sugimoto, and S. Narisawa, "Numerical evaluation of the capping tendency of microcrystalline cellulose tablets during a diametrical compression test," Int. J. Pharm., vol. 493, no. 1, pp. 182-191, 2015.

[11] A. Krok, P. García-Triñanes, M. Peciar, and C.-Y. Wu, "Finite element analysis of thermomechanical behaviour of powders during tabletting," Chem. 
Eng. Res. Des., vol. 110, pp. 141-151, 2016.

[12] L. H. Han, J. a. Elliott, a. C. Bentham, A. Mills, G. E. Amidon, and B. C. Hancock, "A modified Drucker-Prager Cap model for die compaction simulation of pharmaceutical powders," Int. J. Solids Struct., vol. 45, no. 10, pp. 3088-3106, 2008.

[13] A. Krok, M. Peciar, and R. Fekete, "Numerical investigation into the influence of the punch shape on the mechanical behavior of pharmaceutical powders during compaction," Particuology, vol. 16, pp. 116-131, Oct. 2014.

[14] I. C. Sinka, J. C. Cunningham, and A. Zavaliangos, "The effect of wall friction in the compaction of pharmaceutical tablets with curved faces: A validation study of the Drucker-Prager Cap model," Powder Technol., vol. 133, no. 1-3, pp. 33-43, 2003.

[15] F. Podczeck, "Methods for the practical determination of the mechanical strength of tablets?From empiricism to science," Int. J. Pharm., vol. 436, no. 1-2, pp. 214-232, Oct. 2012.

[16] V. Mazel, H. Diarra, V. Busignies, and P. Tchoreloff, "Evolution of the DieWall Pressure during the Compression of Biconvex Tablets: Experimental Results and Comparison with FEM Simulation.," J. Pharm. Sci., vol. 104, no. 12, pp. 4339-44, Dec. 2015.

[17] H. Nakamura, Y. Sugino, T. Iwasaki, and S. Watano, "Development of a Novel Tablet Machine for a Tiny Amount of Powder and Evaluation of Capping Tendency," Chem. Pharm. Bull. (Tokyo)., vol. 59, no. 12, pp. 15181522, Dec. 2011.

[18] R. Kuppuswamy, S. R. Anderson, L. L. Augsburger, and S. W. Hoag, "Estimation of capping incidence by indentation fracture tests.," AAPS PharmSci, vol. 3, no. 1, p. E5, 2001.

[19] C. Y. Wu, O. M. Ruddy, a. C. Bentham, B. C. Hancock, S. M. Best, and J. a. Elliott, "Modelling the mechanical behaviour of pharmaceutical powders 
during compaction," Powder Technol., vol. 152, no. 1-3, pp. 107-117, 2005.

[20] K. Sugimori, S. Mori, and Y. Kawashima, "Characterization of die wall pressure to predict capping of flat- or convex-faced drug tablets of various sizes," Powder Technol., vol. 58, no. 4, pp. 259-264, 1989.

[21] K. Sugimori, S. Mori, and Y. Kawashima, "The role of binders in the prevention of capping within a tablet.," Chem. Pharm. Bull. (Tokyo)., vol. 37, no. 4, pp. 1064-1067, Apr. 1989.

[22] H. Diarra, V. Mazel, V. Busignies, and P. Tchoreloff, "Investigating the effect of tablet thickness and punch curvature on density distribution using finite elements method," Int. J. Pharm., vol. 493, no. 1, pp. 121-128, 2015.

[23] A. Krok, M. Peciar, and R. Fekete, "Particuology Numerical investigation into the influence of the punch shape on the mechanical behavior of pharmaceutical powders during compaction,” vol. 16, pp. 116-131, 2014.

[24] S. Keshavarz, A. R. Khoei, and Z. Molaeinia, "Genetic algorithm-based numerical optimization of powder compaction process with temperaturedependent cap plasticity model," Int. J. Adv. Manuf. Technol., vol. 64, no. 58, pp. 1057-1072, 2013.

[25] A. R. Khoei, S. Keshavarz, and A. R. Khaloo, "The genetic algorithm approach for shape optimization of powder compaction processes considering contact friction and cap plasticity models," Eng. Comput., vol. 27, no. 3, pp. 322-353, 2010.

[26] A. R. Khoei, S. Keshavarz, and S. O. R. Biabanaki, "Optimal design of powder compaction processes via genetic algorithm technique," Finite Elem. Anal. Des., vol. 46, no. 10, pp. 843-861, 2010.

[27] A. Baroutaji, M. D. Gilchrist, D. Smyth, and A. G. Olabi, "Crush analysis and multi-objective optimization design for circular tube under quasi-static lateral loading," Thin-Walled Struct., vol. 86, pp. 121-131, 2015.

[28] A. Baroutaji, M. D. Gilchrist, D. Smyth, and A. G. Olabi, "Analysis and 
optimization of sandwich tubes energy absorbers under lateral loading," Int. J. Impact Eng., vol. 82, pp. 74-88, Aug. 2015.

[29] A. Baroutaji, E. Morris, and A. G. Olabi, "Quasi-static response and multiobjective crashworthiness optimization of oblong tube under lateral loading," Thin-Walled Struct., vol. 82, pp. 262-277, Sep. 2014.

[30] M. Sajjia, K. Y. Benyounis, and A. G. Olabi, "The simulation and optimization of heat treatment of cobalt ferrite nanoparticles prepared by the sol-gel technique," Powder Technol., vol. 222, pp. 143-151, 2012.

[31] D. Drucker and W. Prager, "Soil mechanics and plastic analysis or limit design," Q. Appl. Math., vol. 10, pp. 157-165, 1952.

[32] A. Baroutaji, S. Lenihan, and K. Bryan, "Combination of finite element method and Drucker-Prager Cap material model for simulation of pharmaceutical tableting process," Materwiss. Werksttech., vol. 48, no. 11, pp. 1133-1145, Dec. 2017.

[33] H. Diarra, V. Mazel, A. Boillon, L. Rehault, V. Busignies, S. Bureau, and P. Tchoreloff, "Finite Element Method (FEM) modeling of the powder compaction of cosmetic products: Comparison between simulated and experimental results," Powder Technol., vol. 224, pp. 233-240, 2012.

[34] J. M. Newton, I. Haririan, and F. Podczeck, "The influence of punch curvature on the mechanical properties of compacted powders," Powder Technol., vol. 107, no. 1-2, pp. 79-83, Jan. 2000.

[35] V. Mazel, H. Diarra, J. Malvestio, and P. Tchoreloff, "Lamination of biconvex tablets: Numerical and experimental study," Int. J. Pharm., vol. 542, no. 1-2, pp. 66-71, 2018. 
Figure 1: Stress and Mohr's circle for a tablet after the decompression stage
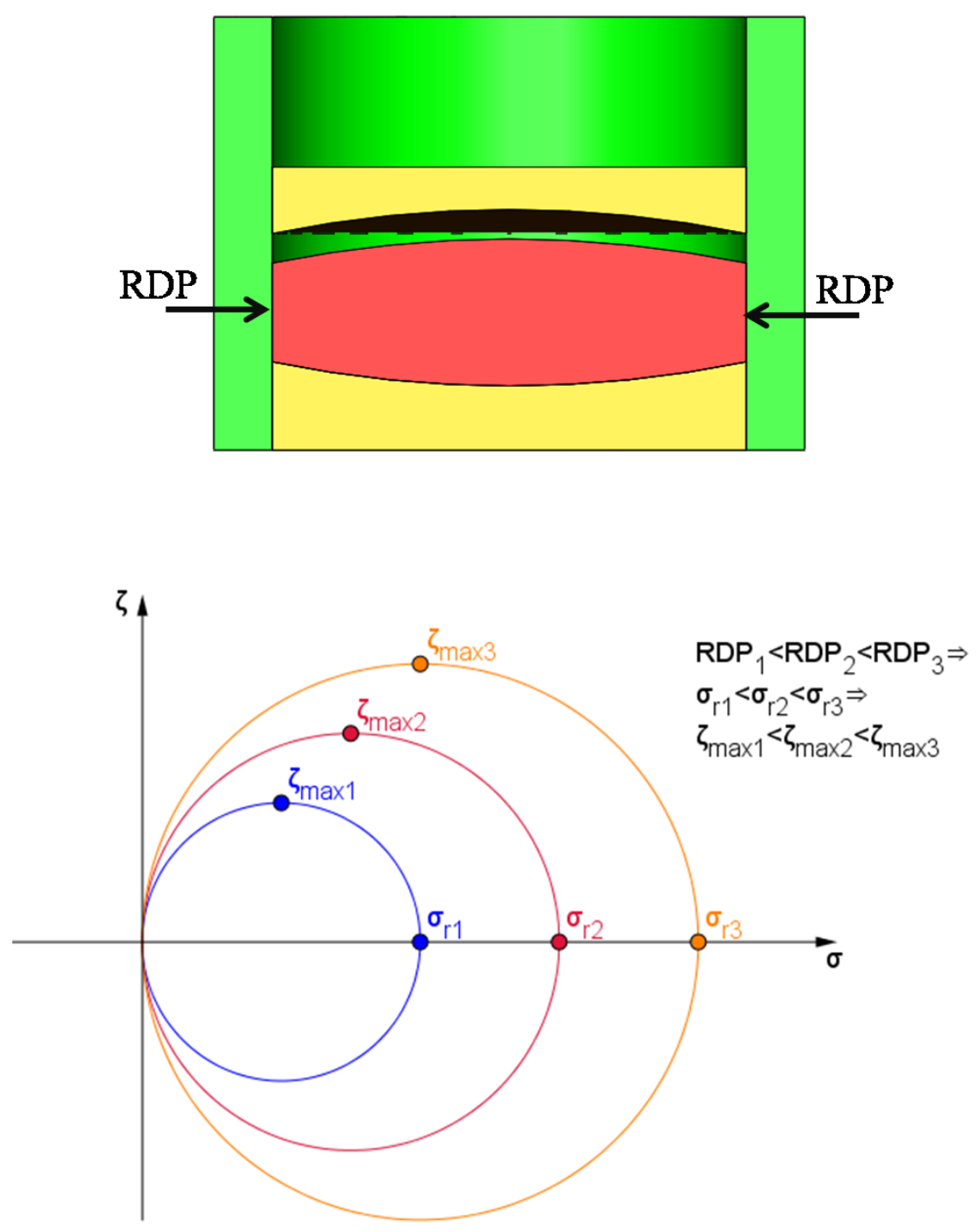
Figure 2: Flow chart of optimisation scheme using the desirability approach

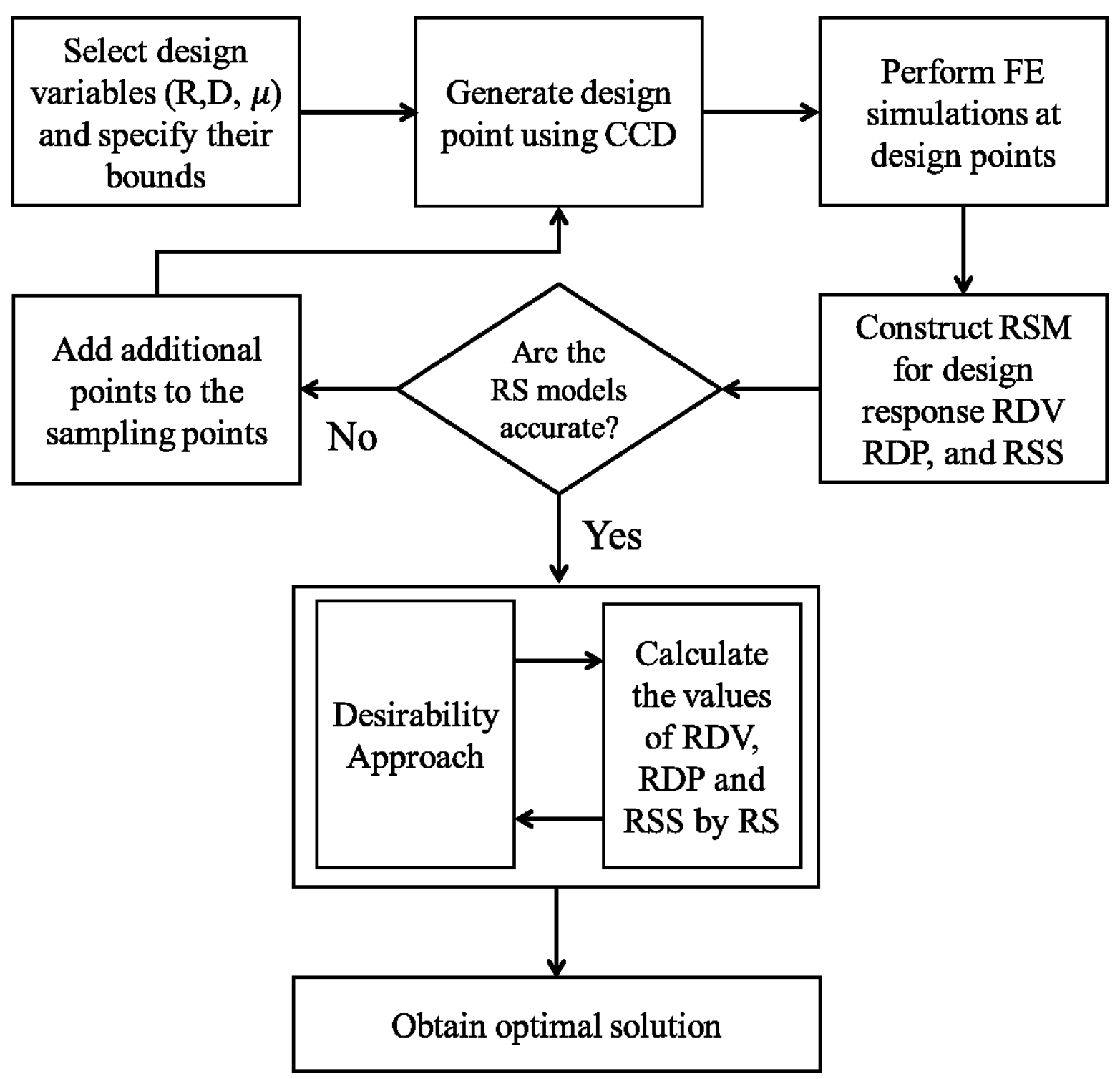


Figure 3: 2D Axisymmetric FE model for (a) FF table and (b) CF tablet

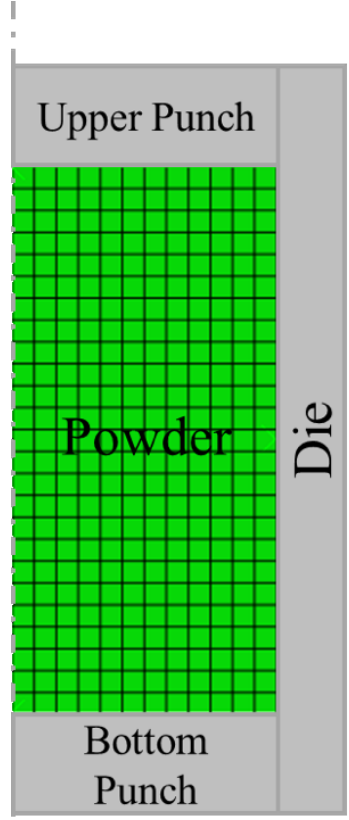

(a)

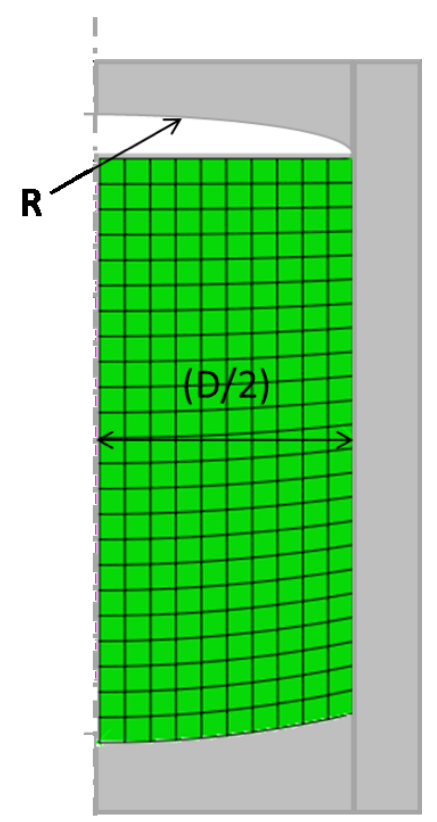

(b) 
Figure 4: Comparison of experimental and numerical simulations: (a) axial pressure vs axial displacement, (b) tablet thickness vs compaction pressure

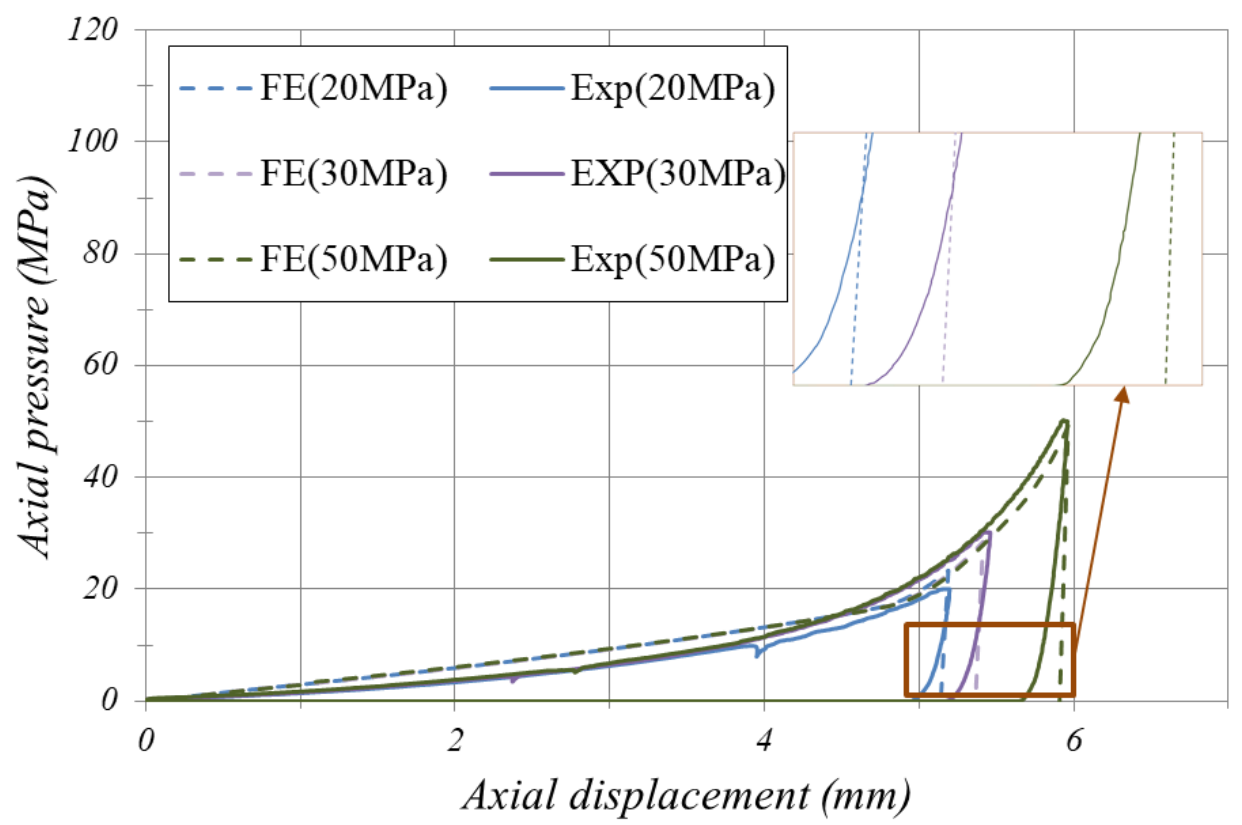

(a)

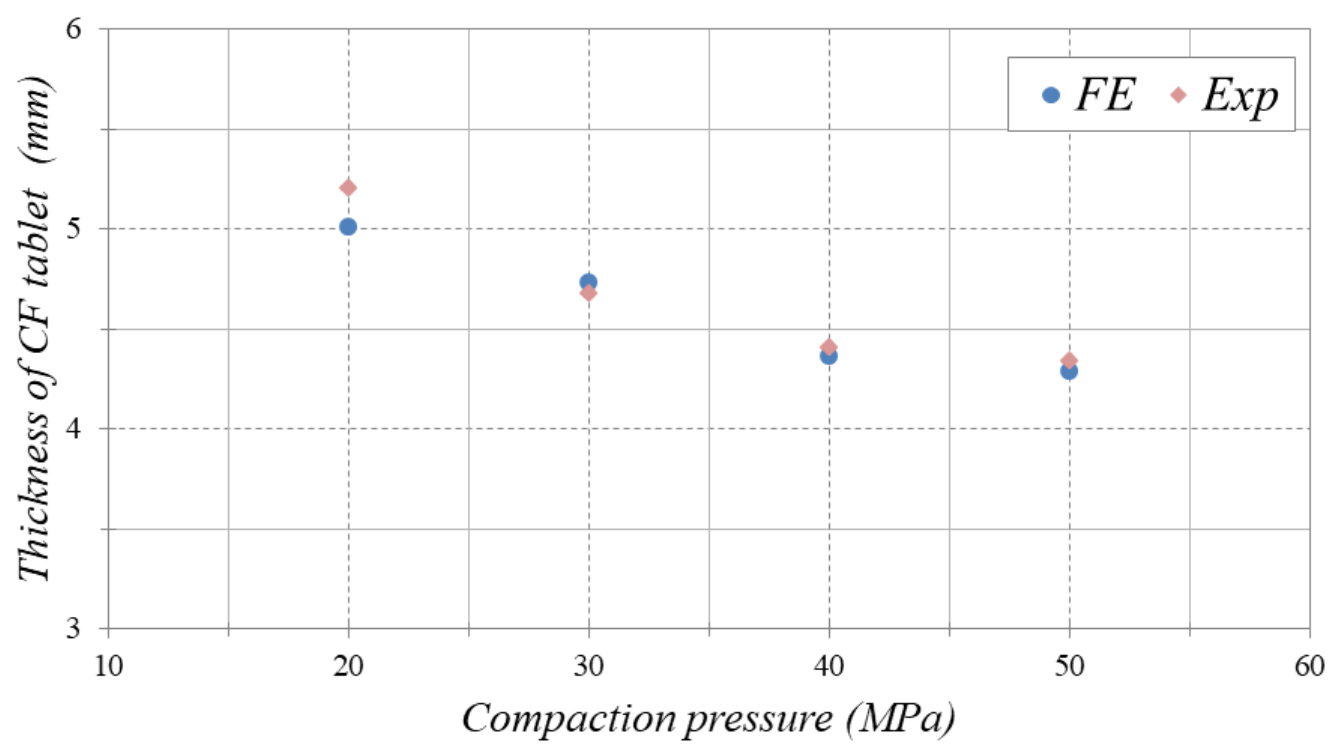

(b) 
Figure 5: Comparison of numerical values (gained from FE simulations) against predicted values (calculate from RS models) at the design points.
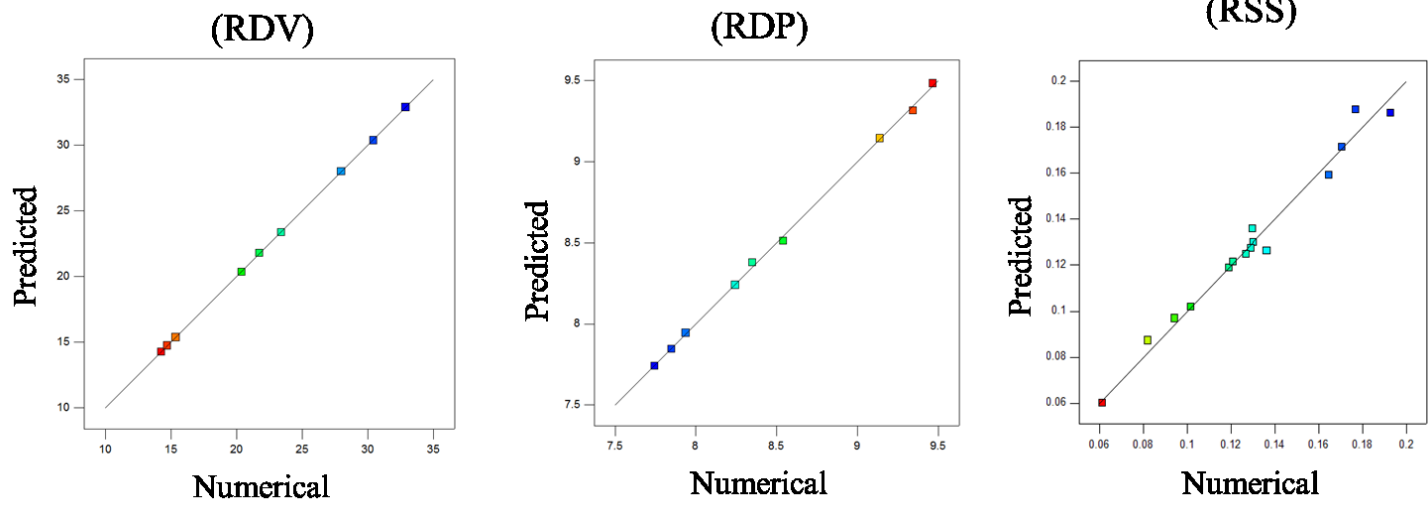
Figure 6: Relative Density (RD) distribution for various CF tablets at the end of decompression
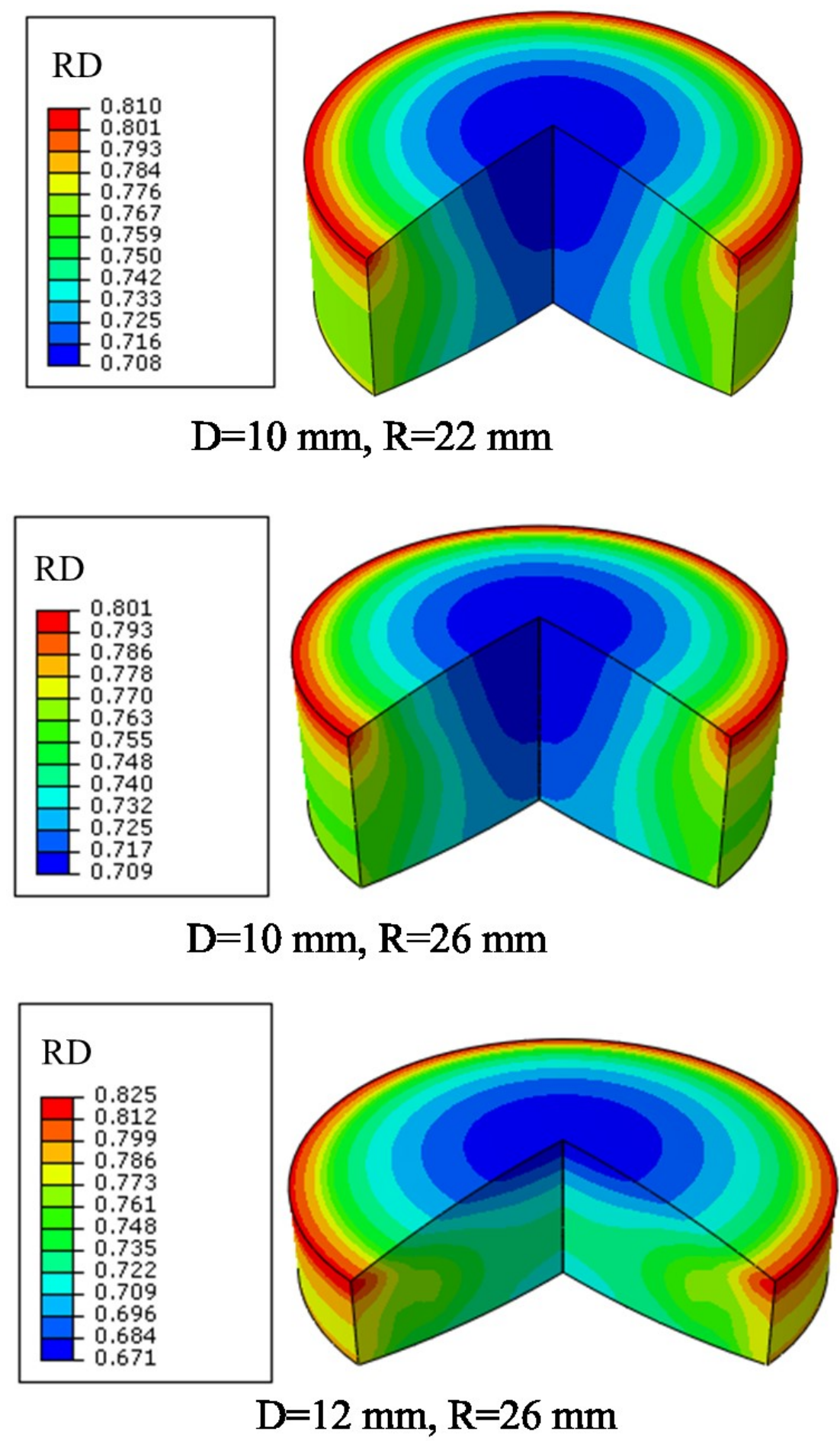
Figure 7: Variation of RDV with $\mathrm{D}$ and $\mathrm{R}$ within $\mathrm{CF}$ tablets

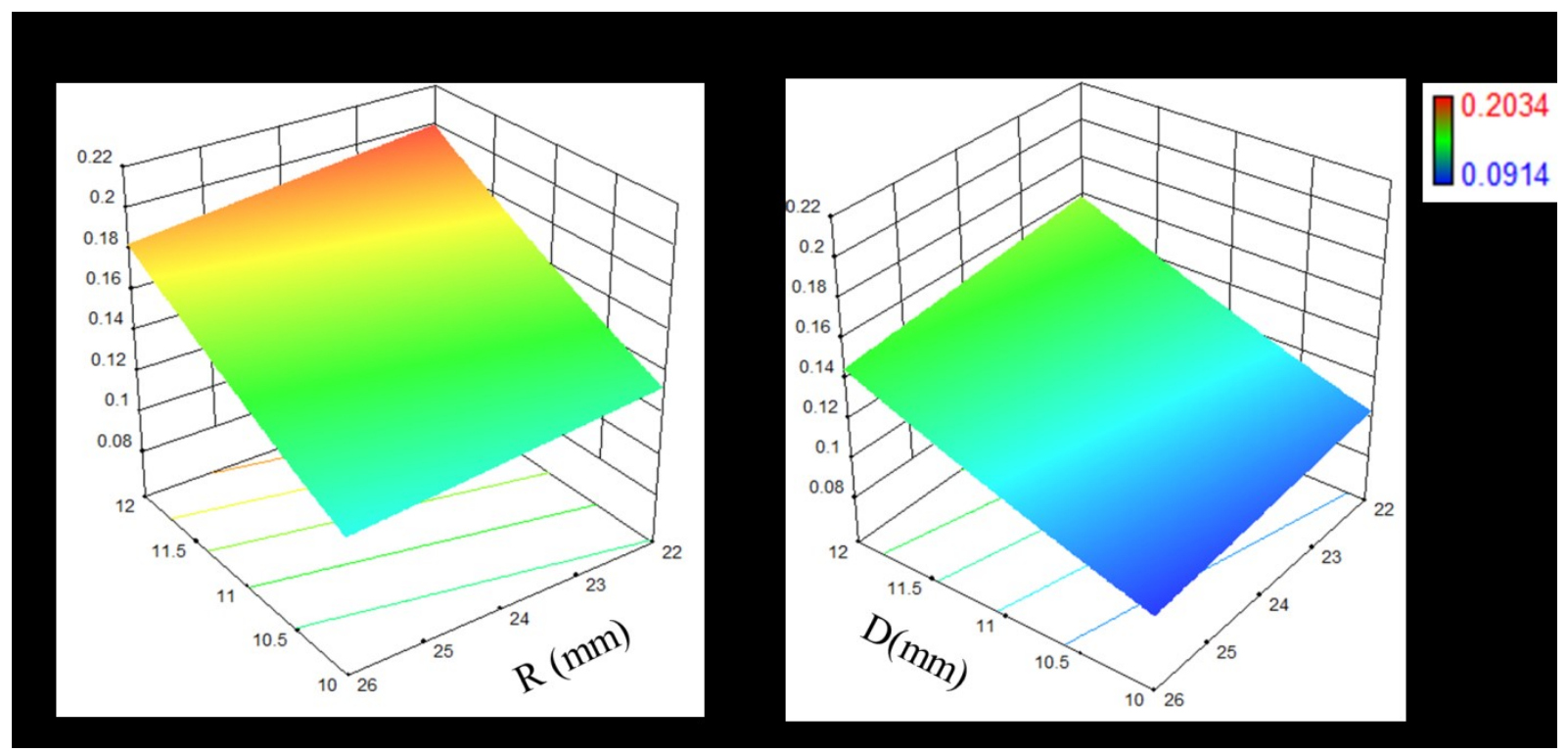


Figure 8: Schematic diagram of punch face with different sizes

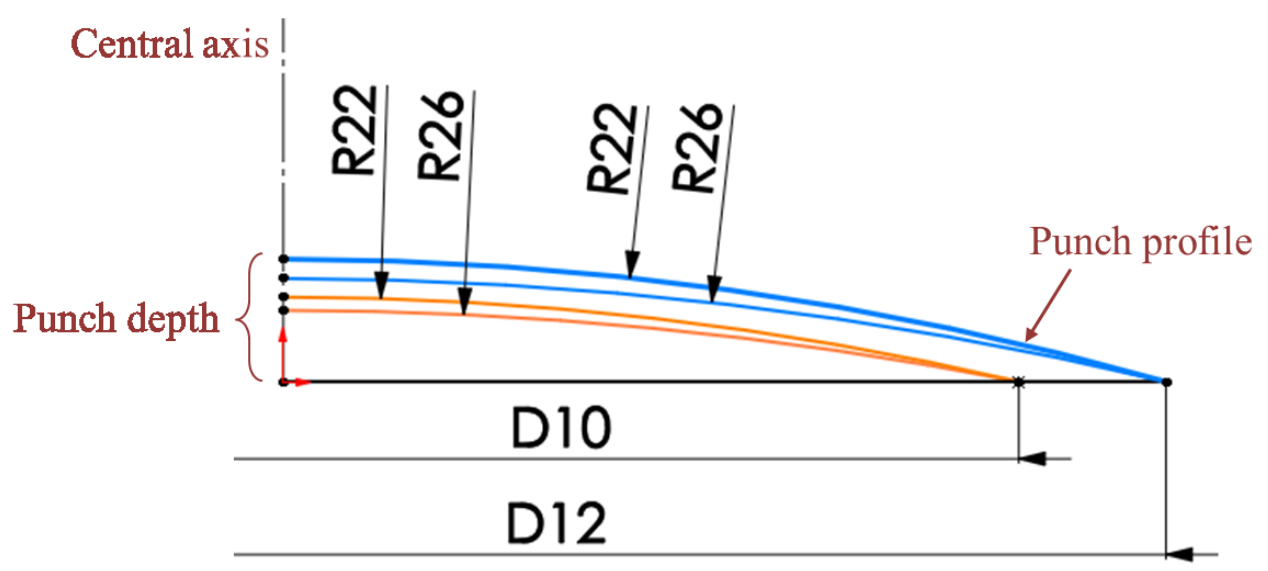


Figure 9: Variation of RDP with D and R within CF tablets

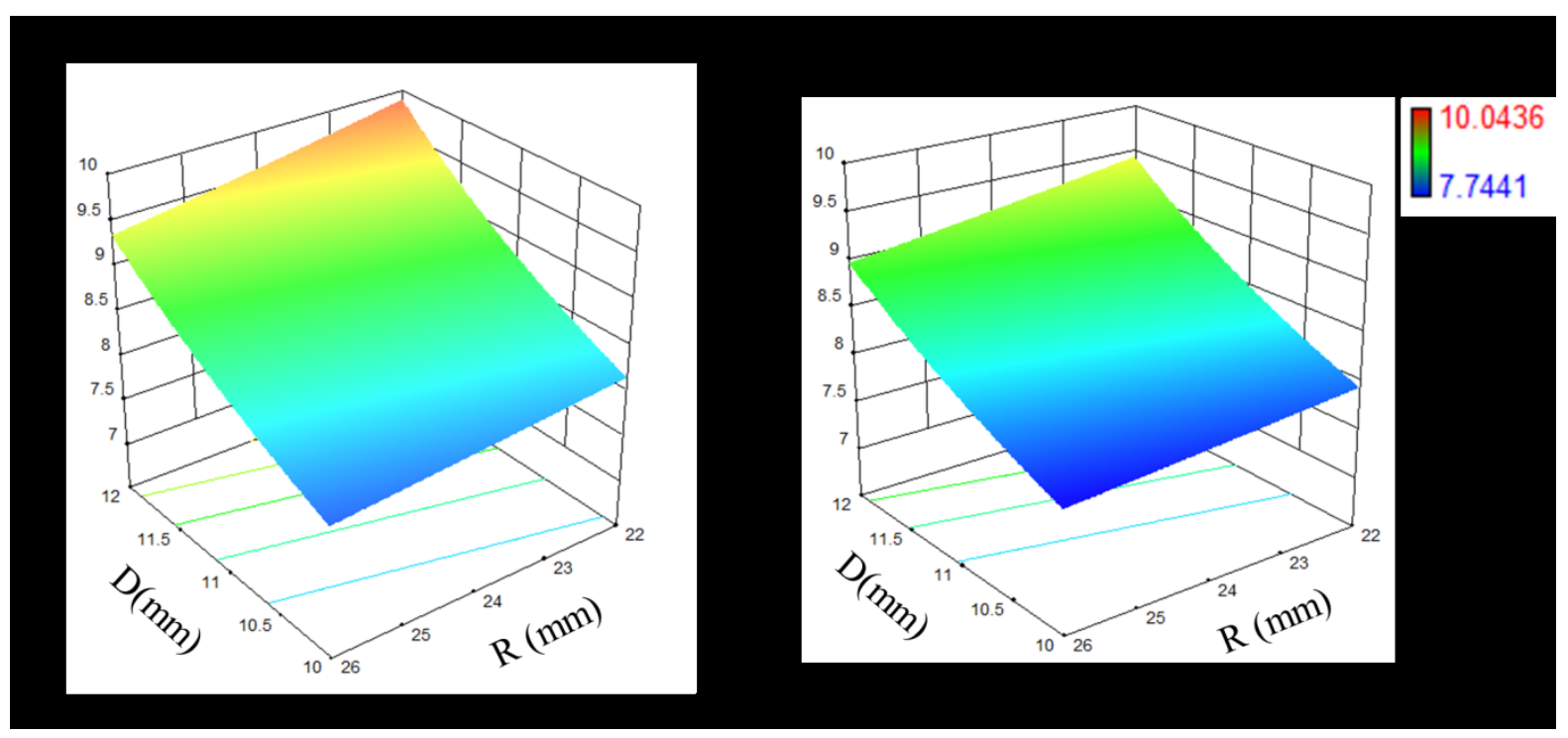


Figure 10: Axial stress distribution at the end of decompression
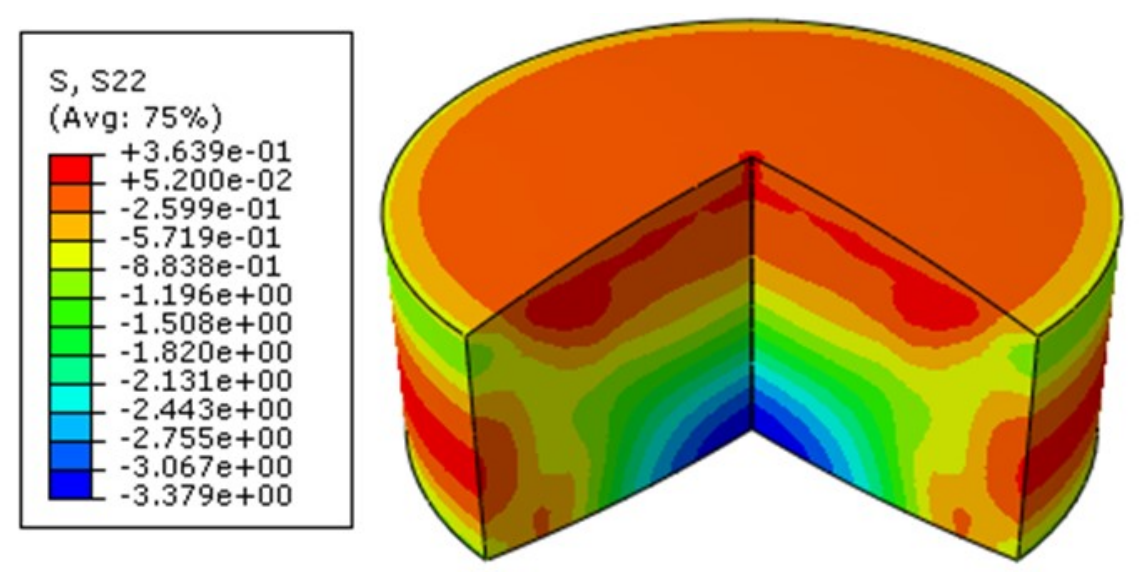

\section{$\mathrm{D}=10 \mathrm{~mm} . \mathrm{R}=26 \mathrm{~mm}$}
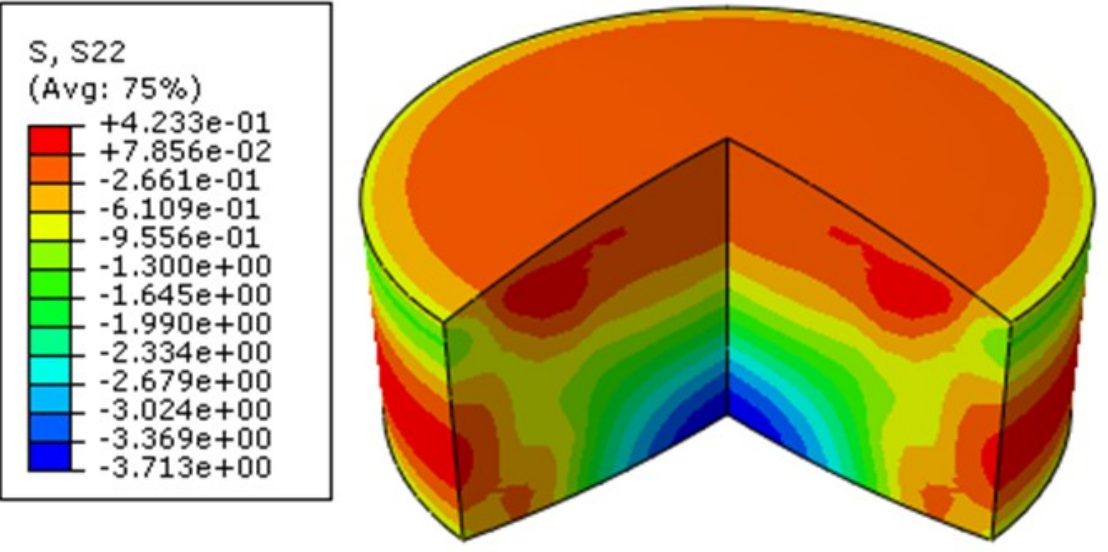

\section{$\mathrm{D}=10 \mathrm{~mm}, \mathrm{R}=22 \mathrm{~mm}$}
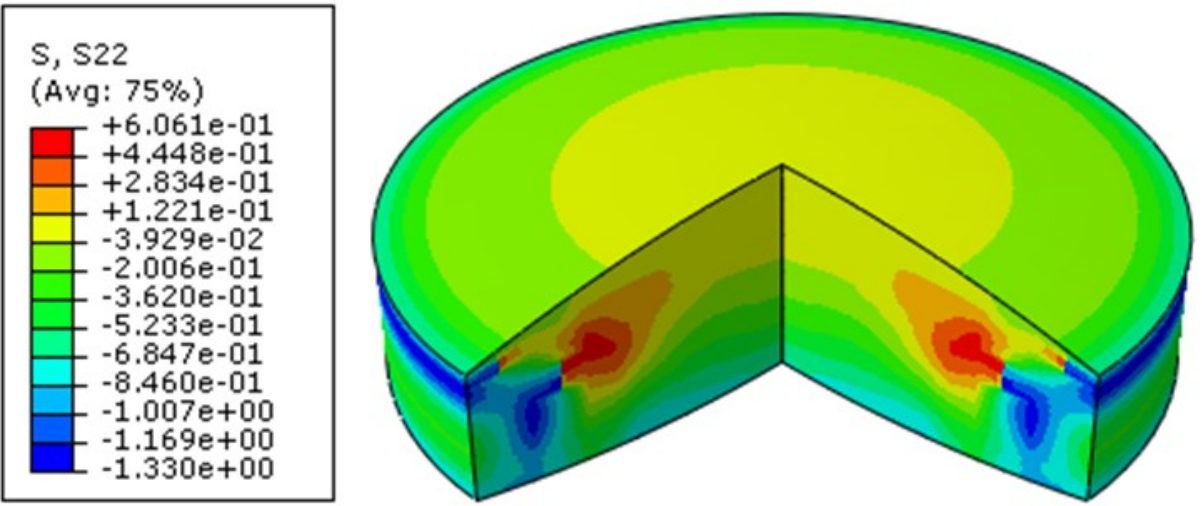

$\mathrm{D}=12 \mathrm{~mm}, \mathrm{R}=26 \mathrm{~mm}$ 
Figure 11: Shear stress distribution within the tablet as it emerge from the die
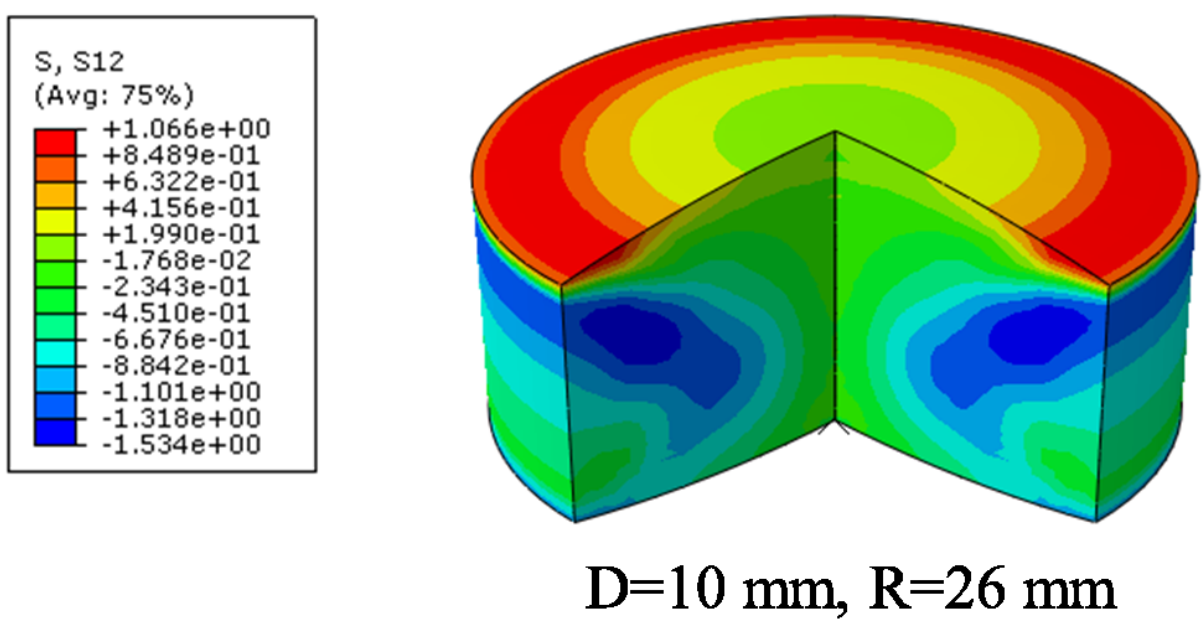

\section{S, $\$ 12$ \\ (Avg: $75 \%$ )}

$+1.214 \mathrm{e}+00$

$+9.739 \mathrm{e}-01$

$+7.338 \mathrm{e}-01$

$+4.938 \mathrm{e}-01$

$+2.537 \mathrm{e}-01$

$+1.357 \mathrm{e}-02$

$-2.265 \mathrm{e}-01$

$-4.666 e-01$

$7.067 e-01$

$-9.468 \mathrm{e}-01$

$-1.187 \mathrm{e}+00$

$-1.427 e+00$

$-1.667 e+00$

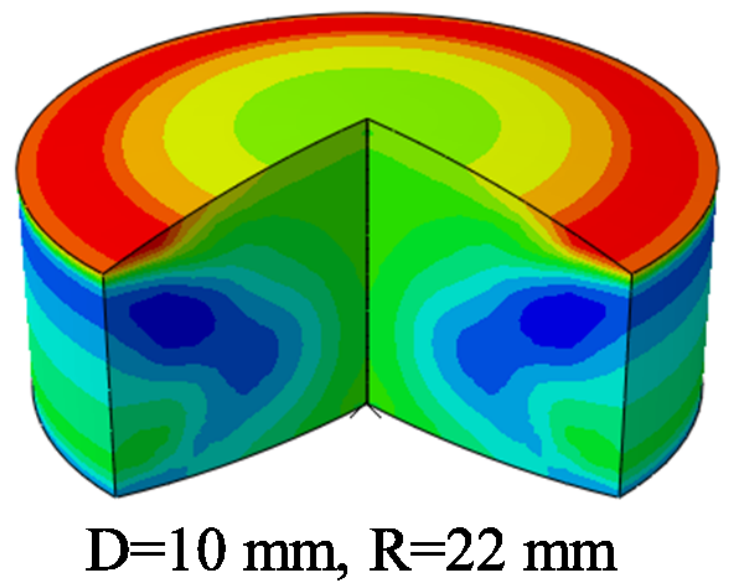

\section{S, $\$ 12$ \\ (Avg: $75 \%$ )}

$+1.220 \mathrm{e}+00$

$+1.000 \mathrm{e}+00$

$+7.804 \mathrm{e}-01$

$+5.606 \mathrm{e}-01$

$+3.408 \mathrm{e}-01$

$+1.210 \mathrm{e}-01$

$-9.876 \mathrm{e}-02$

$-3.186 \mathrm{e}-01$

$-5.383 e-01$

$-7.581 \mathrm{e}-01$

$-9.779 \mathrm{e}-01$

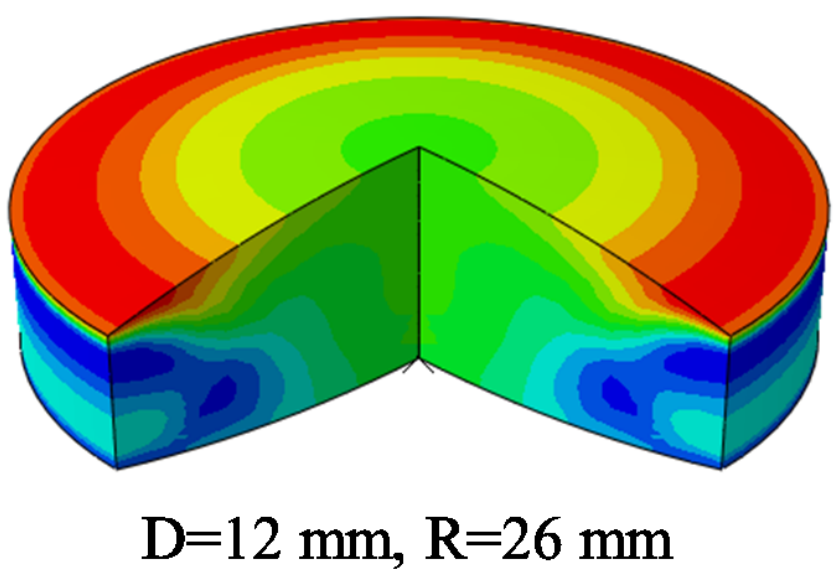


Figure 12: Variation of RSS with D and R

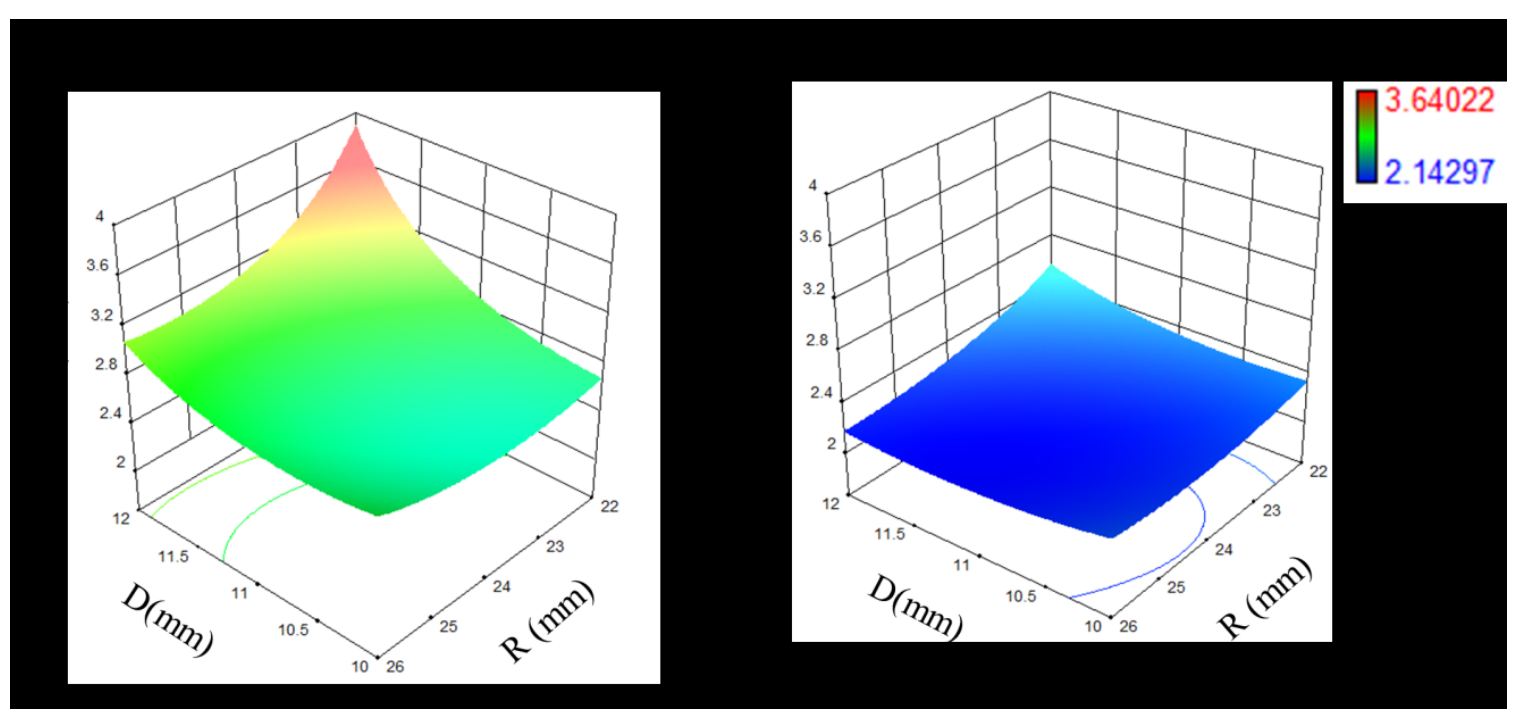


Figure 13: Desirability objective vs geometrical parameters
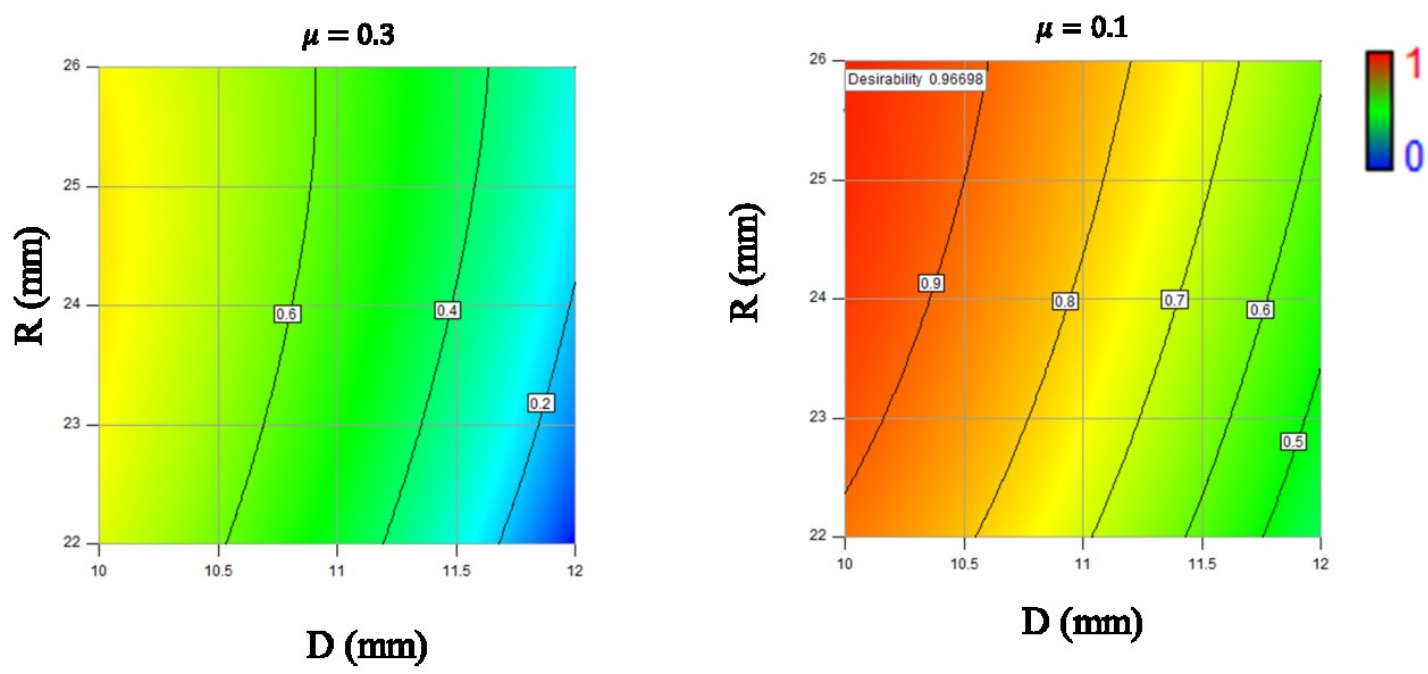
Figure 14: Comparison of FF and optimal CF tablets: (a) Relative Density (RD) distribution (b) Shear stress distribution within the tablet as it emerge from the die (c) radial pressure vs compaction pressure

\section{FF tablet}

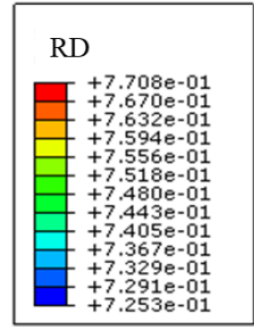

Optimal CF tablet

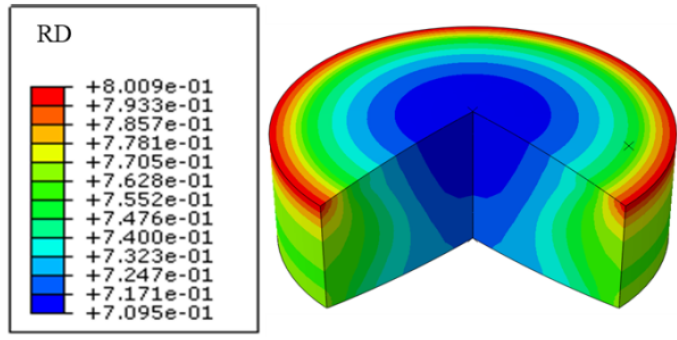

(a)

\section{FF tablet}

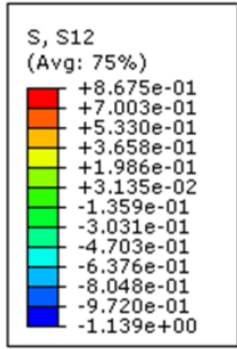

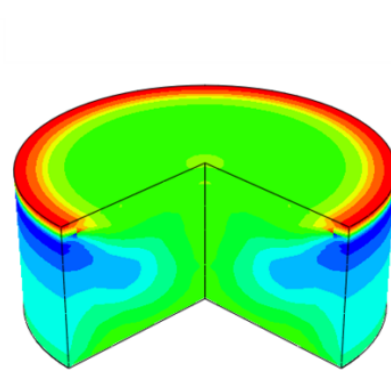

\section{Optimal CF tablet}
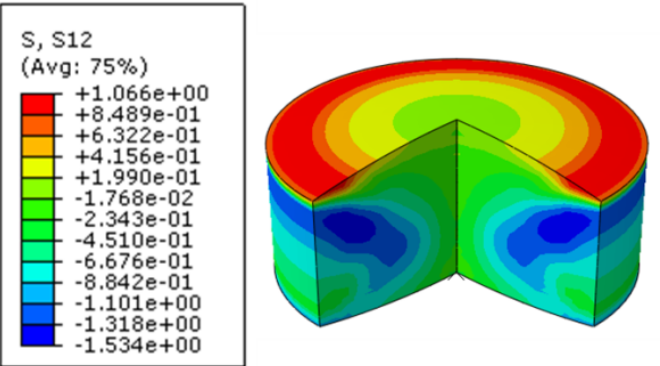

(b)

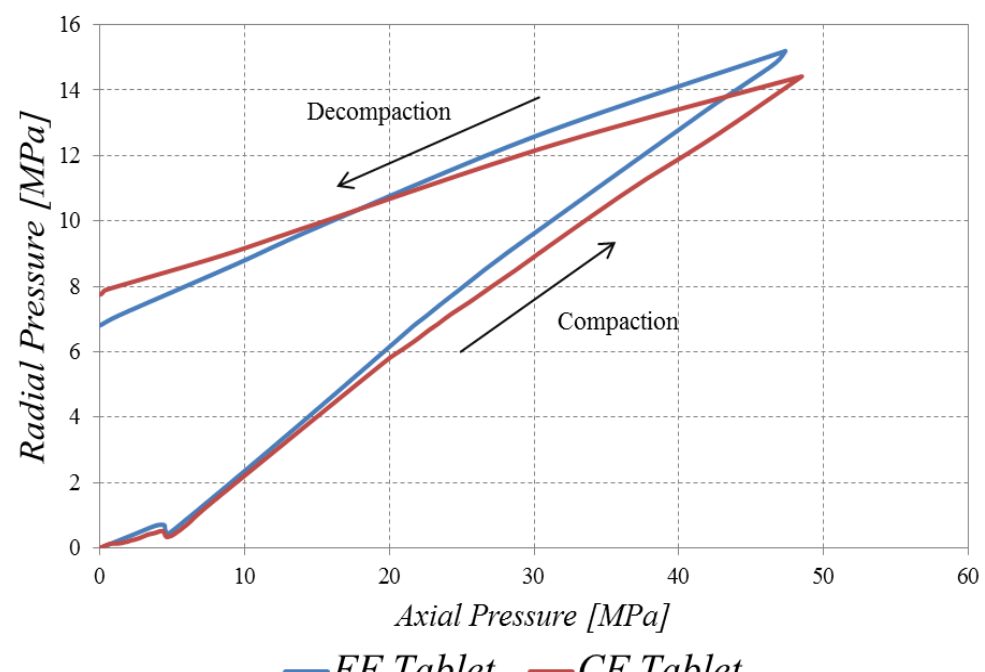

(c) 
Table 1: Design variables with their associated upper and lower limits

\begin{tabular}{|c|c|c|}
\hline \multicolumn{2}{|c|}{} & \\
\hline Design variable & Lower limit & Upper limit \\
\hline $\mathrm{D}$ & $10 \mathrm{~mm}$ & $12 \mathrm{~mm}$ \\
\hline $\mathrm{R}$ & $22 \mathrm{~mm}$ & $26 \mathrm{~mm}$ \\
\hline$(\mu$ & 0.1 & 0.3 \\
\hline
\end{tabular}


Table 2: Design matrix

\begin{tabular}{|c|c|c|c|c|c|c|}
\hline Run & $D$ & $R$ & $\mu$ & $R D V$ & $R D P$ & $R S S$ \\
\hline 1 & 11 & 24 & 0.1 & 0.121 & 8.349 & 2.231 \\
\hline 2 & 10 & 22 & 0.3 & 0.138 & 8.270 & 2.575 \\
\hline 3 & 12 & 24 & 0.2 & 0.180 & 9.474 & 2.984 \\
\hline 4 & 12 & 22 & 0.1 & 0.162 & 9.465 & 2.571 \\
\hline 5 & 12 & 26 & 0.3 & 0.179 & 9.310 & 3.180 \\
\hline 6 & 10 & 24 & 0.2 & 0.118 & 7.974 & 2.582 \\
\hline 7 & 11 & 24 & 0.3 & 0.146 & 8.538 & 2.516 \\
\hline 8 & 11 & 22 & 0.2 & 0.144 & 8.645 & 2.880 \\
\hline 9 & 11 & 24 & 0.2 & 0.138 & 8.454 & 2.602 \\
\hline 10 & 10 & 22 & 0.1 & 0.102 & 7.937 & 2.305 \\
\hline 11 & 12 & 22 & 0.3 & 0.203 & 10.044 & 3.640 \\
\hline 12 & 10 & 26 & 0.1 & 0.091 & 7.744 & 2.269 \\
\hline 13 & 12 & 26 & 0.1 & 0.154 & 9.138 & 2.143 \\
\hline 14 & 11 & 26 & 0.2 & 0.130 & 8.292 & 2.660 \\
\hline 15 & 10 & 26 & 0.3 & 0.128 & 7.970 & 2.679 \\
\hline
\end{tabular}


Table 3: Summary of ANOVA analysis for the generated models of RDV, RDP, and RSS responses

\begin{tabular}{|c|c|c|c|c|c|c|}
\hline \multirow{2}{*}{ Model } & \multirow{2}{*}{ F-Value } & \multirow{2}{*}{ P-Value } & \multicolumn{4}{|c|}{ Statistical measurements } \\
\cline { 5 - 7 } & & & $R^{2}$ & Adj- $R^{2}$ & Pre- $R^{2}$ & Adeq Precision \\
\hline$R D V=f(D, R, \mu)$ & 107.94 & $<0.0001$ & 0.96 & 0.95 & 0.93 & 33.673 \\
\hline$R D P=f(D, R, \mu)$ & 210.09 & $<0.0001$ & 0.98 & 0.97 & 0.96 & 42.187 \\
\hline$R S S=f(D, R, \mu)$ & 27.22 & 0.001 & 0.98 & 0.94 & 0.75 & 18.25 \\
\hline
\end{tabular}


Table 4: Validation data of RS models of RDV, RDP, and RSS responses

\begin{tabular}{|c|c|c|c|c|c|c|c|}
\hline & $D$ & $R$ & $\mu$ & & $R D V$ & $R D P$ & $R S S$ \\
\hline \multirow{3}{*}{$C P 1$} & \multirow{3}{*}{10.5} & \multirow{3}{*}{23} & \multirow{3}{*}{0.1} & FEM & 0.112 & 8.070 & 2.32 \\
\hline & & & & RSM & 0.111 & 8.121 & 2.28 \\
\hline & & & & Error (\%) & 0.893 & 0.630 & 1.17 \\
\hline \multirow{3}{*}{$C P 2$} & \multirow{3}{*}{10.5} & \multirow{3}{*}{25} & \multirow{3}{*}{0.1} & FEM & 0.106 & 8.019 & 2.2 \\
\hline & & & & RSM & 0.105 & 8.001 & 2.143 \\
\hline & & & & Error $(\%)$ & 1.160 & 0.215 & 2.5 \\
\hline \multirow{3}{*}{$C P 3$} & \multirow{3}{*}{11.5} & \multirow{3}{*}{23} & \multirow{3}{*}{0.3} & FEM & 0.182 & 9.28 & 3.01 \\
\hline & & & & RSM & 0.179 & 9.25 & 2.98 \\
\hline & & & & Error (\%) & 1.6 & 0.3 & 0.9 \\
\hline
\end{tabular}

